JPdK Volume 3 Nomor 1 Tahun 2021 Halaman 13-20

JURNAL PENDIDIKAN dan KONSELING

Research \& Learning in Faculty of Education

\title{
Pengaruh Model Pembelajaran Think Talk Write (TTW) Terhadap Kemampuan Kerja Sama Siswa Sekolah Dasar
}

\author{
Susfa Welli Kuntala ${ }^{1}$, Amir Luthfi ${ }^{2}$, Sumianto ${ }^{3}$ \\ Program Studi Pendidikan Guru Sekolah Dasar \\ Fakultas Ilmu Pendidikan \\ Universitas Pahlawan Tuanku Tambusai \\ Email: susfawelli@gmail.com
}

\begin{abstract}
Abstrak
Penelitian ini dilatarbelakangi oleh rendahnya kemampuan kerja sama siswa sama belajar berkelompok pada tema pahlawanku di kelas IV SD Negeri 007 Pulau Lawas. Salah satu solusi untuk mengatasi masalah ini adalah dengan menggunakan model pembelajaran Think Talk Write (TTW). Tujuan penelitian ini untuk mengetahui seberapa besar pengaruh model pembelajaran think talk write (TTW) terhadap kemampuan kerja sama siswa SD Negeri 007 Pulau Lawas. Metode dalam penelitian ini adalah quasi eksperimen dan desain digunakan adalah non-equivalent control group desiain. Sampel penelitian berjumlah 20 siswa di kelas eksperimen yang menerapkan model pembelajaran think talk write (TTW). dan 20 siswa di kelas kontrol dengan menerapkan model pembelajaran konversional. Teknik pengambilan sampel ini menggunakan teknik sampling purposive. Teknik pengumpulan data dengan menggunakan instrumenlembar observasi kemampuan kerja sama siswa. Analisis data menggunakan uji t menggunakan program SPSS for windows version 17.0. Dilihat pada hasil uji t setelah diberikan prilakuan kemampuan kerja sama di kelas eksperimen dan kontrol dilihat pada kolom $t$-test for equality of mean dengan nilai Sig. (2-tailed) 0,040 <0,05 maka dapat di ambil kesimpulan bahwa terdapat pengaruh signitifikan kemampuan kerja sama dengan menggunakan model pembelajaran think talk write (TTW)
\end{abstract}

Kata Kunci: Model pembelajaran Think Talk Write (TTW), Kemampuan kerja sama.

\begin{abstract}
Abstrak
This research was motivated by the low cooperation ability of students in group learning on the theme of my hero in grade IV SD Negeri 007 Pulau Lawas. One solution to overcome this problem is to use the Think Talk Write (TTW) learning model. The purpose of this study was to determine how much influence the think talk write (TTW) learning model has on the cooperation ability of students of SD Negeri 007 Pulau Lawas. The method in this research is a quasi experiment and the design used is a non-equivalent control group design. The research sample consisted of 20 students in the experimental class who applied the think talk write (TTW) learning model. and 20 students in the control class by applying the conventional learning model. This sampling technique using purposive sampling technique. The data collection technique used the observation sheet instrument of the student's cooperation ability. Data analysis used t test using SPSS for windows version 17.0. Judging from the t-test results after being given the treatment ability of cooperation in the experimental and control classes, it is seen in the t-test column for equality of mean with the Sig. (2-tailed) $0.040<0.05$, it
\end{abstract}


can be concluded that there is a significant effect on the ability to work together using the think talk write (TTW) learning model.

Keywords: Think Talk Write (TTW) learning model, cooperation ability.

\section{PENDAHULUAN}

Pendidikan pada hakikatnya adalah usaha sadar yang dilakukuan oleh manusia untuk mengembangkan pengetahuan dan kepribadiannya. Pendidikan ini memiliki peranan penting dalam membina manusia yang memiliki pengetahuan dan keterampilan, serta manusia-manusia yang memiliki sikap positif terhadap segala hal, sehingga dapat dikatakan bahwa pendidikan merupakan satu usaha yang sangat penting dan dianggap pokok dalam kehidupan manusia. Tercapainya tujuan pendidikan di Indonesia tidak terlepas dari kurikulum, peran guru, siswa, masyarakat maupun lembaga terkait lainnya. Peningkatan kualitas menuju tercapainya tujuan tersebut perlu disampaikan suatu upaya perbaikan sistem pembelajaran inovatif yang merangsang siswa untuk mencintai yang akhirnya mau mempelajari seksama terhadap suatu kajian ilmu. Keberhasilan pendidikan sangat ditentukan manakala pendidik tersebut dapat mengubah diri siswa. Perubahan tersebut dalam arti dapat menumbuh kembangkan potensipotensi yang dimiliki siswa sehingga siswa dapat memperoleh manfaatnya secara langsung dalam perkembangan pribadinya. Agar tercapainya tujuan Pendidikan, maka diperlukan adanya kerja sama yang baik Antara guru dan siswa. Kerja sama yaitu suatu aspek dalam ilmu sosial yait sosialemosional. Adapun menurut Magta (2019:213) berpendapat menggemukakan bahwa kerja sama merupakan salah satu kemampuan dalam pola prilaku atau berprilaku sosial. Semakin banyak kesempatan yang anak miliki untuk melakukan dan menyelesaikan suatu hal secara bersama-sama, maka semakin cepat siswa belajar melakukan pekerjaan dengan cara bekerja sama. Agar kerja sama dapat terdukung dengan baik, pada anak usia dini perilaku sosial berkaitan dengan konsep sosial terhadap teman sebaya maupun orang tua perlu diberikan bimbingan. Dengan demikian, kemampuan untuk melakukan kemampuan kerja sama yang dimulai dari anak mampu mengenal perilaku saling tolong menolong dan saling memahami sesama teman. Perilaku pada anak usia dini khusus SD Penting untuk dilakukan agar terpenuhi aspek sosial emosional yang berhungan dengan prilaku sosial. Berkaitan dengan hal di atas bahwa kemampuan kerja sama sangat penting dalam proses pembelajaran. Pembelajaran bisa membawa anak untuk saling menghargai pendapat temannya, mampu meningkatkan rasa empati dengan saling bantu membantu.

Kemampuan yang harus di tingkatkan oleh siswa antara lain memberikan masukan dengan bahasa yang baik dan sopan. Tidak menyinggung perasaan teman dan memberikan efek pada pendapat yang diberikan tersebut. Selain itu kemampuan kerja sama saling membantu sama lain bukan berarti berkerja sama dalam hal menyontek, akan tetapi kerja sama bersifat bersama-sama mencari tahu menyelesaikan permasalahan. Adapun indikator kerja sama menurut Magta (2019:210) a.saling membantu sesama anggota dalam berkelompok b.Setiap anggota ikut memecahkan masalah dalam kelompok sehingga mencapai kesepakatan c. Menghargai kontribusi setiap anggota kelompok d. Berada dalam kelompok kerja saat kegiatan berlangsung memberikan kesempatan siswa lain untuk berpartisipasi dalam tugas kelompok. Berdasarkan hasil observasi, yang dilakukan kedua kelas tersebut, maka terlihat adanya permasalahan pada kemampuan kerja sama siswa. Apabila siswa tidak memiliki kemampuan kerja sama maka siswa kurang menghargai pendapat 
yang diberikan teman, kurang peka dengan lingkungan dan akan mendapatkan hasil belajar yang kurang maksimal yang akan berdampak di kemudian hari.

Menurut Hurlock (Fauziddin 2016:37) menjelaskan bahwa kemapuan kerja sama merupakan kemampuan bekerja sama dengan orang lain untuk memperoleh suatu imbalan bersama. Kerja sama dapat dilihat ketika sekelompok orang melakukan tugas secara bersama-sama dan ditandai dengan adanya interaksi positif seperti kegiatan saling membantu dan saling berbagi untuk mencapai tujuan bersama. Menurut pratiwi (2017: 178) kemampuan kerja sama dapat diartikan sebagai kemampuan yang dilakukan oleh beberapa siswa untuk saling membantu satu sama lain sehingga tampak kebersamaan dan kekompakan untuk mencapai tujuan bersama.Menurut Apriono (2011: 103) menjelaskan kemampuan kerja sama dapat diartikan sebagai kemampuan yang dilakukan oleh beberapa siswa untuk saling membantu satu sama lain sehingga tampak kebersamaan dan kekompakan untuk mencapai tujuan bersama.

Berdasarkan permasalahan tersebut peneliti mencoba menerapkan model Think Talk Write (TTW) dalam mengatasi permasalahan tersebut. Huinker dan Laughlin Ryanti (2016: 14). Model pembelajaran Think Talk Write (TTW) merupakan perencanaan dan tindakan yang cermat mengenai kegiatan pembelajaran, yaitu melalui kegiatan berpikir (think), aktivitas berpikir (think) dapat dilihat dari proses membaca suatu teks bacaan, suatu materi pembelajaran kemudian membuat catatan apa yang telah dibaca. Dalam tahap ini siswa secara individu memikirkan

kemungkinan jawaban (strategi penyelesaian), membuat catatan apa yang telah dibaca (write), baik itu berupa apa yang diketahuinya, maupun langkah-langkah dalam penyelesaian dalam bahasanya sendiri. Menurut Khusna (2017: 138) menyatakan "Think Talk Write" merupakan model pembelajaran kooperatif yang kegiatan pembelajarannya yaitu lewat kegiatan berfikir (think), berbicara/berdiskusi (talk), bertukar pendapat (talk) serta menuliskan hasil diskusi (write) agar tujuan pembelajaran dan kompetensi yang diharapkan dapat tercapai. Adapun faktorfaktor yang mempengaruhi kemampuan kerja sama siswaMenurut Asmah dan Yulianti (2016:33) sebagai berikut:

1. Keluarga, keluarga merupakan lingkungan pertama yang memberikan pengaruh terhadap berbagai aspek perkembangan anak termasuk perkembangan sosialnya. Hubungan antara orangtua dan anak sangat penting untuk membangun kepercayaan terhadap orang lain dan diri sendiri. Selain itu juga dapat membantu perkembangan sosial dan emosional pada anak. Hubungan antara orangtua dan anak yang hangat, terbuka, dan komunikatif akan meningkatkan rasa percaya diri dan juga performa di sekolah maupun lingkungan masyarakat. Selain itu anak akan lebih terhindar dari hal-hal negatif.

2. Kematangan, bersosialisasi dengan baik diperlukan kematangan fisik dan psikis sehingga mampu mempertimbangkan proses sosial. Memberi dan menerima nasehat orang lain memerlukan kematangan intelektual dan emosional, disamping itu kematangan dalam berbahasa juga sangat menentukan.

3. Status Sosial Ekonomi, kehidupan sosial banyak dipengaruhi oleh kondisi sosial ekonomi keluarga dalam masyarakat. Perilaku anak akan banyak memperhatikan kondisi yang telah ditanamkan oleh keluarganya.

4. Kapasitas Mental (Emosi dan Intelegensi), kemampuan berfikir dapat mempengaruhi banyak hal, seperti kemampuan belajar memecahkan masalah dan berbahasa. Perkembangan emosi berpengaruh sekali terhadap perkembangan sosial anak. Anak yang berkemampuan intelek tinggi akan berkemampuan bahasa dengan baik. Oleh karena itu jika perkembangan 
5. Pendidikan, pendidikan merupakan proses sosialisasi anak yang terarah. Hakekat pendidikan sebagai proses pengoperasian ilmu yang normatif. Anak memberikan warna kehidupan mereka dimasa yang akan datang.

\section{METODOLOGI PENELITIAN}

Penelitian ini dilaksanakan di SD Negeri 006 Pulau Lawas Kabupaten Kampar pada kelas $\mathrm{VI}_{\mathrm{A}}$ dan $\mathrm{VI}_{\mathrm{B}}$ yang berjumlah 20 siswa di kelas $\mathrm{VI}_{\mathrm{A}}$ dan 20 siswa di kelas VIв. Penelitian ini merupakan penelitian quasi eksperimen. Bentuk penelitian ini adalah desain penelitian nonequivalent control group design. Menurut Sugiyono (2015: 12) menyatakan bahwa "desain ini hampir sama dengan pretest-posttest control group, hanya pada penelitian ini kelompok eksperimen maupun control tidak dipilih secara random".

Tabel 1

Desain Penelitian Posttest Only Desain With Nonequivalent Group

\begin{tabular}{|c|c|c|c|}
\hline Kelas & Pengukuran & Perlakuan & $\begin{array}{c}\text { Posttest dan } \\
\text { Prettest }\end{array}$ \\
\hline Eksperimen & $\mathrm{O}_{1}$ & $\mathrm{X}_{1}$ & $\mathrm{O}_{4}$ \\
\hline Kontrol & $\mathrm{O}_{3}$ & - & $\mathrm{O}_{2}$ \\
\hline
\end{tabular}

Sumber: Sugiyono (2016)

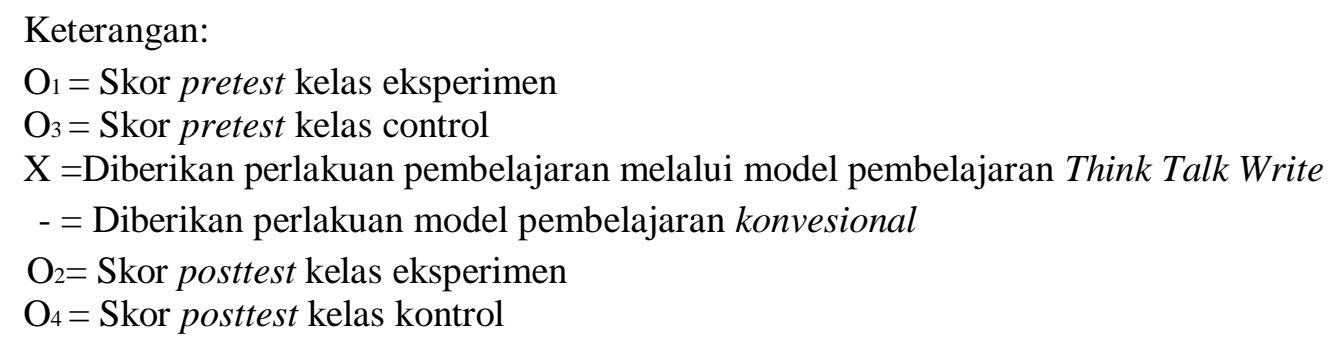

Teknik pengumpulan data pada penelitian ini adalah teknik pengumpulan data yang menggunakan wawancara, lembar observasi kemampuan kerja sama, dokumentasi.

\section{HASIL PENELITIAN DAN PEMBAHASAN}

Data nilai po sttest pada kelas eksperimen dan kontrol sangat berbeda. Pada kelas eksperimen setelah diberikan perlakuan dengan menggunakan model pembelajaran Think Talk Write (TTW), yang memperolehkan nilai posttest dengan nilai tertinggi sebesar 95 dan nilai terendah sebesar 60. Sebelum melakukan pengujian hipotesis statistik, terlebih dahulu dilakukan pengujian persyaratan analisis yaitu data hasil posstest pengaruh model pembelajaran Think Talk Write (TTW) terhadap kemampuan kerja sama siswa di kelas eksperimen dan model pembelajaran konversional di kelas kontrol. Uji persyaratan analisis adalah uji normalitas, homogenitas dan uji t.

1. Uji Normalitas

Uji nilai posstest dari hasil lembar observasi kemampuan kerja sama siswa pada kelas eksperimen dan kelas kontrol. Uji normalitas data pada penelitian ini menggunakan uji normalitas Kolmogorovsmirnov dengan nilai $\alpha=0,05$ dengan menggunakan bantuan program Statistical Package For Social Sciences (SPSS 17). Adapun hasil perhitungan uji normalitas dapat dilihat dalam tabel 3 sebagai berikut: 
Tabel 3

Hasil Uji Normalitas Data Posttest Kelas Eksperimen dan Kontrol One-Sample Kolmogorov-Smirnov Test

\begin{tabular}{|c|c|c|c|}
\hline \multicolumn{4}{|c|}{ One-Sample Kolmogorov-Smirnov Test } \\
\hline & & $\begin{array}{c}\text { Nilai } \\
\text { posttest } \\
\text { Eksperi } \\
\text { men }\end{array}$ & $\begin{array}{c}\text { Nilai } \\
\text { posttest } \\
\text { kontrol }\end{array}$ \\
\hline \multicolumn{2}{|l|}{$\mathrm{N}$} & 20 & 20 \\
\hline \multirow{3}{*}{$\begin{array}{l}\text { Normal } \\
\text { Parameters }\end{array}$} & Mean & 80.00 & 74.75 \\
\hline & Std Dariotion & 0007 & 6501 \\
\hline & Std. Deviation & 0.004 & 0.584 \\
\hline \multirow{3}{*}{$\begin{array}{l}\text { Most Extreme } \\
\text { Differences }\end{array}$} & Absolute & .250 & .215 \\
\hline & Positive & .200 & .215 \\
\hline & Negative & -.250 & -.137 \\
\hline \multicolumn{2}{|c|}{ Kolmogorov-Smirnov Z } & 1.118 & .960 \\
\hline \multicolumn{2}{|c|}{ Asymp. Sig. (2-tailed) } & .164 & .315 \\
\hline
\end{tabular}

Berdasarkan pada tabel 4.10 hasil perhitungan posttest kemampuan kerja sama siswa kelas eksperimen dan kelas kontrol, dengan bantuan program SPSS for windows dan kelas kontrol adalah berdistribusi normal. Hal ini terlihat dari Asymp. Sig. (2tailed) di kedua kelas lebih dari nilai singnifikansi 0,05 yaitu $0,164(0,164>0,05)$ di terima dan $\mathrm{H}_{\mathrm{A}}$ ditolak yakni data berdistribusi normal. 1. Uji Homogenitas

Uji homogenitas posttestdilakukan untuk mengetahui apakah kelas eksperimen dan kelas kontrol memiliki varians sama (homogen) atau tidak sama (tidak homogen) setelah mendapatkan perilakuan yang berbeda. Uji homogenitas juga diperlukan Untuk menentukan apakah nilai kelas eksperimen dan kelas kontrol homogen yaitu dengan menggunakan cara Analyze Compare MeansOneway Anova. Hasil perhitungan uji homogenitas varians nilai posttest dapat
17,0 menggunakan teknik One Sampel Kolmogorov Smirnov, menunjukkan bahwa data posttest kelas ekaperimen

di kelas eksperimen dan $0,315(0,315)>$ $0,05)$ di kelas kontrol. Dengan ini hipotesis yang berlaku adalah Ho

dilihat pada lampiran 24 dalam tabel 4 sebagai berikut:

Tabel 4 Hasil Uji Homogenitas Data Posttest Kelas Eksperimen dan Kontrol

\begin{tabular}{|c|l|l|c|}
\hline \multicolumn{4}{|c|}{ Test of Homogeneity of Variances } \\
\hline \multicolumn{4}{|c|}{ Nilai Posttest eksperimen dan control } \\
\hline Levene Statistic & f1 & f2 & Sig. \\
\hline 5.445 & 3 & 14 & .211 \\
\hline
\end{tabular}


Dari tabel 4 dapat diketahui nilai signifikan posttest kelas eksperimen dan kontrol sebesar 0,211. Nilai ini menunjukkan bahwa nilai signifikan posttest lebih besar taraf singnifikansi $5 \%$ nilai (sig $>\alpha=0,211$

\section{Uji t}

Uji hipotesis dilakukan untuk mengetahui perbandingan data antara sebelum dan sesudah perlakuan yakni untuk mengetahui adanya perbedaan antara pengaruh model pembelajaran Think Talk Write (TTW) terhadap kemampuan kerja sama siswa, serta membandingkan kelompok kontrol dan kelompok eksperimen. Pengujian hipotesis ini menggunakan independent sampel t-test
$>$ 0,05), maka dapat disimpulkan bahwa nilai posttest kedua kelas mempunyai varian yang sama (homogen). Maka dapat disimpulkan bahwa Ho terima dan $\mathrm{Ha}$ ditolak, artinya kelompok eksperimen dan kelompok kontrol mempunyai varians yang sama.

dalam program statistik SPSS versi 17.0 Independent sampel t-test digunakan untuk menguji perbedaan rata-rata dari dua kelompok data atau sampel yang independen. Adapun olahan data posttest dari eksperimen dan kelas kontrol dapat di lihat pada tabel 4.13 berikut:

Tabel 5 Hasil Uji t Posttest Kelas Eksperimen dan Kelas Kontrol

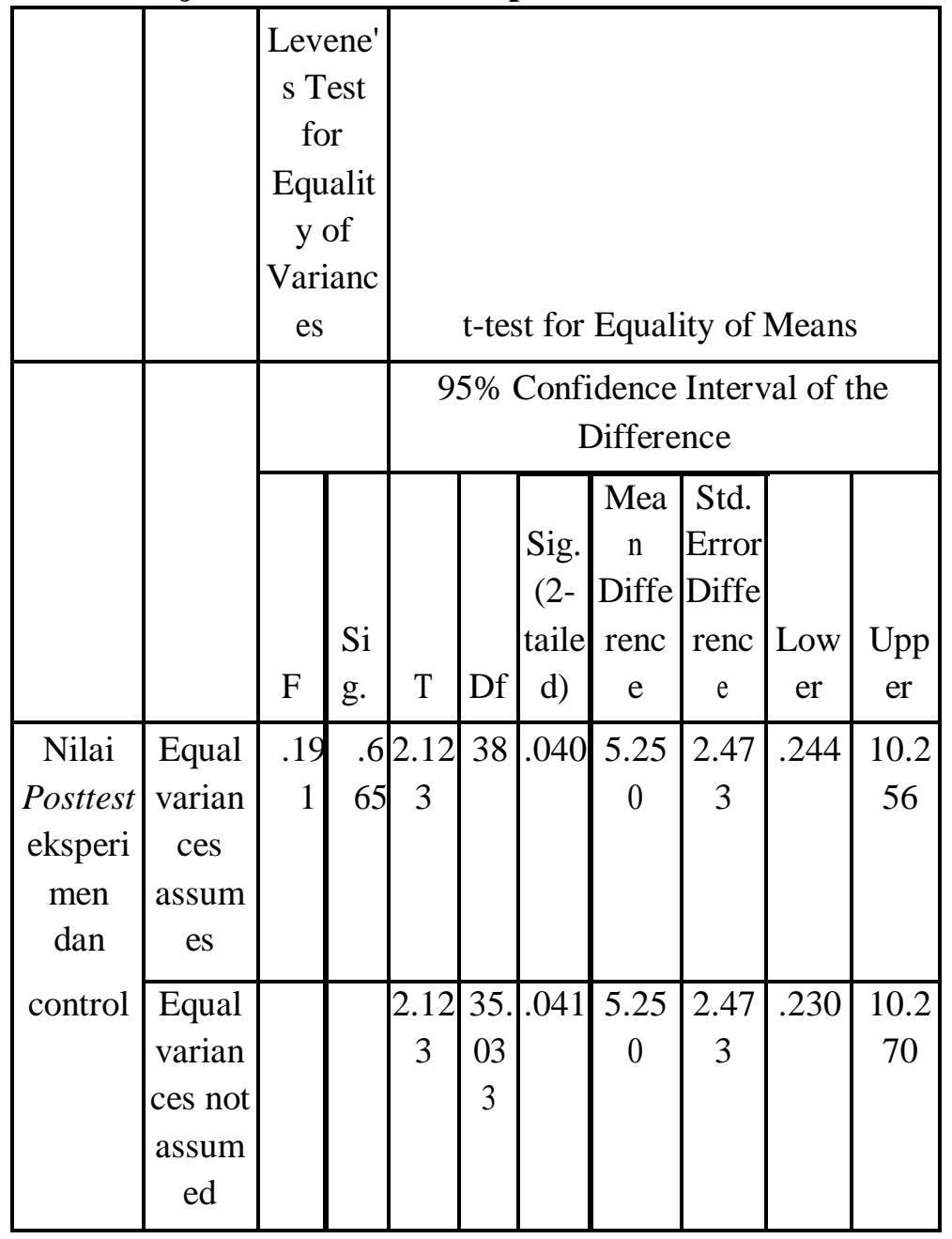

Sumber: Data Olahan Penelitian 2020 
Data tabel 5 dapat simpulkan bahwa varian adalah homogen atau mempunyai varian yang sama. Homogenitas ini dapat dilihat pada kolam Levene's Test for Equality of Variances yang menujukkan nilai sig. lebih besar dari taraf signifikansi ( $\alpha$ ) 0,05 yaitu 0,665 . Nilai $t_{\mathrm{g}}$ yang dapatkan dari tabel 4.14 sebesar 2,123. Nilai thitung negatif berarti ratarata grup 1 (kontrol) lebih rendah dari pada rata-rata grup 2 (eksperimen). Perbedaan ratarata (mean difference 5,250 dan perbedaan berkisar antara 0,244 sampai 10,256 (lihat pada lower dan upper). Hasil uji t

\section{SIMPULAN}

Terdapat pengaruh yang signifikan terhadap kemampuan kerja sama siswa dengan model pembelajaran Think Talk Write (TTW) di bandingkan pembelajaran menggunakan model pembelajaran Think Talk Write. Hal ini dapat dilihat berdasarkan pengujian hipotesis dengan menggunakan $\mathrm{t}$ test dengan taraf singnifikansi 5\% memperolehkan nilai sig (2-tailed) sebanyak $(0,040)<\propto(0,05)$. Nilai sig $(2$-tailed $)<$

\section{DAFTAR PUSTAKA}

Apriono, D. (2011). Pembelajaran

Kolaboratif: Suatu Landasan untuk

Membangun Kebersamaan dan Keterampilan. Diklus,

Edisi XVII, (2). 293-303.

Asmah \& Yulianti,. (2016). Pengaruh Strategi PDR Terhadap Active Learning dan Kemampuan Berkerjasama Anak Usia Dini. Jurnal Pedagogi. Vol 2, (3), 65-75.

Fauziddin, M,. (2013). Peningkatan Kemampuan Kerja Sama Melalui Kegiatan Kerja Kelompok Pada Anak Kelompok A TK Kartika Salo Kabupaten Kampar. Jurnal PGPAUD Stkip PTT. Vol, 2. (1). 29-45.

Khusna, A. et al. (2017) . Penerapan Model Pembelajaran Think Talk Write (TTW) Berbantu Media CD Interaktif pada Mata Pelajaran Ipa Terhadap Hasil Belajar siswa.Jurnal Penelitian Ilmu Pendidikan. Vol 10, (2), 136-147. untukmengetahui perbedaan hasil posttest kemampuan kerja sama siswa kelas eksperimen dan kelas kontrol dilihat pada kolom t-test for Equality of Means dengan nilai Sig. (2-tailed) 0,040. Adapun kriteria pengujian hipotesis adalah jika nilai sig. (2tailed) $<0,05$ maka Ho ditolak dan $\mathrm{Ha}$ diterima. Hal ini berarti bahwa terdapat perbedaan yang singnifikan antara kemampuan kerja sama siswa dengan menggunakan model pembelajaran Think Talk Write (TTW) dan kemampuan kerja sama siswa dengan menggunakan model pembelajaran

konversion

nilai $\propto \quad$ Yang menunjukkanbahwa

kemampuan kerja sama kedua kelompok berbeda secara singnifikan. Hal ini menunjukan bahwa pengaruh model pembelajaran thik talk write (TTW) terhadap kemampuan kerja sama siswa kelas IV SD Negeri 007 Pulau Lawas.Berdasarkan hasil temuan peneliti dengan menerapkan model pembelajaran Think Talk Write (TTW) dapat meningkatkan kemampuan kerja sama siswa.

Magta. (2019). Pengaruh Metode Proyek Terhadap Kemampuan Kerjasama Anak Kelompok A. Jurnal Mimbar Ilmu. Vol 24, (2), 212-220.

Pratiwi, A. (2018). Peningkatan Kemampuan Kerjasama Melalui Model Project Based Learning (PjBL) Berbantuan Metode Education Pada Mata Pelajaran Ilmu Pengetahuan Sosial. Jurnal Refleksi Edukatika. Vol $8,(2)$.

Ryanti, O. (2016). Penerapan Model Pembelajaran Think Talk Write (TTW) untuk Meningkatkan Aktivitas dan Hasil Belajar Siswa Kelas V Pada Mata Pelajaran IPS SD Negeri 9 Metro Timur Tahun Ajaran 2015/2016. Universitas Lampung.Bandar Lampung: Skripsi Tidak dipublikasikan. 
